Author affiliations and support information (if applicable) appear at the end of this article.

Published at jco.org on August 22, 2017. Corresponding author: Chi-Ling Chen, $\mathrm{PhD}$, Graduate Institute of Clinical Medicine, College of Medicine, National Taiwan University. 7 Chung-Shan South Road, Taipei 100, Taiwan; e-mail: chlnchen@ntu.edu.tw.

(C) 2017 by American Society of Clinical Oncology

0732-183X/17/3530w-3440w/\$20.00

\title{
Long-Term, Supplemental, One-Carbon Metabolism-Related Vitamin B Use in Relation to Lung Cancer Risk in the Vitamins and Lifestyle (VITAL) Cohort
}

Theodore M. Brasky, Emily White, and Chi-Ling Chen

\section{$\begin{array}{llllllll}\text { A } & \text { B } & \mathbf{S} & \mathbf{T} & \mathbf{R} & \mathbf{A} & \mathbf{C} & \mathbf{T}\end{array}$}

\section{Purpose}

Inconsistent findings have been reported of a link between the use of one-carbon metabolismrelated $B$ vitamins and lung cancer risk. Because of the high prevalence of supplemental vitamin $B$ use, any possible increased association warrants further investigation. We examined the association between long-term use of supplemental B vitamins on the one-carbon metabolism pathway and lung cancer risk in the Vitamins and Lifestyle (VITAL) cohort, which was designed specifically to look at supplement use relative to cancer risk.

\section{Methods}

A total of 77,118 participants of the VITAL cohort, 50 to 76 years of age, were recruited between October 2000 and December 2002 and included in this analysis. Incident, primary, invasive lung cancers $(n=808$ ) were ascertained by prospectively linking the participants to a population-based cancer registry. The 10 -year average daily dose from individual and multivitamin supplements were the exposures of primary interest.

\section{Results}

Use of supplemental vitamins $B_{6}$, folate, and $B_{12}$ was not associated with lung cancer risk among women. In contrast, use of vitamin $B_{6}$ and $B_{12}$ from individual supplement sources, but not from multivitamins, was associated with a $30 \%$ to $40 \%$ increase in lung cancer risk among men. When the 10-year average supplement dose was evaluated, there was an almost two-fold increase in lung cancer risk among men in the highest categories of vitamin $\mathrm{B}_{6}$ (>20 mg/d; hazard ratio, 1.82; $95 \% \mathrm{Cl}, 1.25$ to 2.65 ) and $\mathrm{B}_{12}(>55 \mu \mathrm{g} / \mathrm{d}$; hazard ratio, 1.98; $95 \% \mathrm{Cl}, 1.32$ to 2.97 ) compared with nonusers. For vitamin $B_{6}$ and $B_{12}$, the risk was even higher among men who were smoking at baseline. In addition, the $B_{6}$ and $B_{12}$ associations were apparent in all histologic types except adenocarcinoma, which is the type less related to smoking.

\section{Conclusion}

This sex- and source-specific association provides further evidence that vitamin B supplements are not chemopreventive for lung cancer and may be harmful.

\section{J Clin Oncol 35:3440-3448. (c) 2017 by American Society of Clinical Oncology}

\section{INTRODUCTION}

Lung cancer has been top ranked globally in both cancer incidence and mortality for decades, with a substantial proportion of cases occurring in the developed countries, including the United States. ${ }^{1}$ The one-carbon metabolism pathway is considered important for DNA integrity maintenance and gene expression regulation. Several $\mathrm{B}$ vitamins, including $\mathrm{B}_{6}, \mathrm{~B}_{9}$ (folate), and $\mathrm{B}_{12}$ interact with homocysteine and methionine in this complex one-carbon metabolism pathway, and disruption of this process may promote carcinogenesis. ${ }^{2}$
Results from previous studies of an association of $B$ vitamins with lung cancer risk are inconsistent. Randomized trials were limited to short supplementation periods and small numbers of incident lung cancer. However, one recent study by Ebbing et $\mathrm{al}^{3}$ reported a $21 \%$ elevated cancer incidence $(P=.02)$ associated with the use of $\mathrm{B}_{12}$ and $\mathrm{B}_{9}$; the effect was driven almost exclusively by increases in lung cancer incidence.

Using data from a large, prospective cohort specifically designed to study long-term dietary supplements in relation to cancer, we conducted a comprehensive analysis of supplemental B vitamin intake and lung cancer risk. We hypothesized 
that the disturbance of the homeostasis of these vitamins, particularly intakes in excess of the Recommended Dietary Allowance (RDA), could have a profound effect on the cellular environment and physiology (including altered oxidative stress and nucleotide pools), thus leading to a harmful consequence such as carcinogenesis. Given that vitamin supplement use is highly prevalent in the general population, any possible harmful effects warrant further investigation.

\section{METHODS}

\section{Study Population}

Details of the study design and cohort enumeration are given elsewhere. ${ }^{4}$ Briefly, men and women, 50 to 76 years of age at baseline, who lived in the 13-county region in western Washington State covered by the SEER cancer registry were eligible to participate.

We excluded participants with a history of or unknown lung cancer at baseline $(n=590)$, those whose lung cancer diagnosis was noted only on the death certificate with no date of diagnosis $(n=8)$, and participants with lung lymphoma $(\mathrm{n}=2)$ or in situ lung cancer $(\mathrm{n}=1)$. After exclusions, 77,118 participants were available for study.

\section{Supplement Use}

Participants reported their regular intake ( $\geq 1$ per week for $\geq 1$ year) of multivitamins, individual vitamin supplements, and mixtures (eg, B complex) over the 10 years before baseline. For all supplement questions, a close-ended format was used to inquire about current versus past use, frequency and duration of use in the past 10 years, and usual dose per day (for individual supplements and mixtures containing $B_{6}, B_{9}$ [folic acid], and $\mathrm{B}_{12}$ ), and brand or exact nutrient formulations for multivitamins. The 10 -year average daily doses for vitamins $B_{6}, B_{9}$, and $B_{12}$ were calculated by summing intakes from multivitamin preparations and individual vitamin sources and mixtures as follows: $\Sigma($ dose per day $) \times($ days per week/7) $\times$ (years/10). Each user of a vitamin $B_{6}, B_{9}$, or $B_{12}$ supplement was categorized into one of five groups of 10 -year average daily intake (units per day): (1) no use, (2) the first tertile among users, (3) more than the first tertile up to the amount of that nutrient that would be obtained from 10 -year daily use of a common multivitamin formulation (Centrum Silver; Wyeth, Madison NJ), and two groups with more than the amount of that nutrient that would be obtained from 10-year daily use of that multivitamin. This classification ensured that individuals who only consumed a standard multivitamin daily for 10 years could not be classified into the highest two intake groups. The highest two categories were dichotomized at the 60 th percentile (eg, $20 \mathrm{mg} / \mathrm{d}_{\text {for }} \mathrm{B}_{6}$ ) to reflect high dose and very high dose over 10 years. Individual supplements or multivitamin sources of $\mathrm{B}$ vitamins were considered separately to address issues of dose (as discussed) and the potential for other constituents in multivitamins to affect risk.

\section{Diet and Other Covariates}

Usual diet was assessed by a food frequency questionnaire (FFQ) adapted from the questionnaires originally developed for the Women's Health Initiative and other studies. ${ }^{5,6}$ The FFQ captured intakes of 120 food and beverage items and included adjustment questions on types of foods and preparation techniques. In addition to diet and supplement data, we collected information at baseline on lung cancer risk factors. Participants reported their demographic and health-related characteristics, including height and weight (from which body mass index [BMI] was computed), education, family history of lung cancer, and medical history. Participants also answered several questions regarding cigarette smoking, including the age at which they started smoking daily, whether they currently smoked at baseline, the number of cigarettes smoked each day, and the cumulative years of smoking and number of years since quitting. A summary smoking-status variable was also calculated and categorized as never-smoker, former smoker (quit $\geq 10$ years ago), recent smoker (quit $<$ 10 years ago), and current smoker.

\section{Case Ascertainment}

Cohort members were followed for incident lung cancer from baseline to December 31, 2007, with a mean follow-up of 6 years. Incident, primary, invasive lung cancers were ascertained by linking the study cohort to the western Washington SEER cancer registry. All incident cancer diagnosed within the 13-county area of western Washington State (except nonmelanoma skin cancer) are reported to SEER along with stage, histologic subtype, and other tumor characteristics. ${ }^{7}$ Linkage to SEER is based on ranking of the agreement between characteristics common to the Vitamin and Lifestyle (VITAL) cohort and SEER, including name, social security number, date of birth, and so forth. Matches with high concordance were made automatically, whereas visual inspection was performed for matches where some, but not all, criteria matched. As a result, 808 incident invasive lung cancer cases were identified.

\section{Statistical Analyses}

Multivariable-adjusted Cox proportional hazards regression models were used to estimate hazard ratios (HRs) and 95\% CIs for associations between supplemental B vitamins and lung cancer risk. Participants' ages were used as the time metric in regression models, with left truncation for age at baseline. Participants were right censored from the analysis at the earliest date of the following events: withdrawal from the study $(0.03 \%)$, death $(4.9 \%)$, emigration out of the SEER catchment region $(5.4 \%)$, or December 31, 2007, the date of linkage to the SEER registry $(88.6 \%)$. Deaths were ascertained by linkage to the Washington State death file, using procedures similar to the SEER linkage. The US Post Office National Change of Address System was used to identify participants who moved out the study region.

We selected potential confounders, a priori, for adjustment in multivariable regression models, including known or suspected risk factors for lung cancer. To accurately control for smoking, we used a step-wise procedure to select the smoking variables among pack-years, pack-years squared, years of smoking, years of smoking squared, smoking status (ie, the four categories already defined), and age when started smoking, that were associated with lung cancer risk at the $P<.05$ level. ${ }^{8}$ Our final model included years smoked, pack-years, and a squared pack-years term in addition to adjustments for the following characteristics: age, race, education, BMI, alcohol consumption in the past year, history of chronic obstructive pulmonary disease, a personal history of cancer other than lung cancer, number of first-degree relatives with a history of lung cancer, and use of nonsteroidal anti-inflammatory drugs (Table 1). Analyses in women were additionally adjusted for duration of use of combined hormone therapy. Analyses including dietary B vitamins were additionally adjusted for total caloric intake.

We hypothesized a priori that associations between $\mathrm{B}$ vitamins and lung cancer risk would be modified by participants' sex and smoking behavior; therefore, we stratified multivariable regression models by sex. Never smokers were excluded from the smoking-stratified analysis because of the low number of participants with incident lung cancer in that group. To examine whether differences in etiology exist for supplemental B vitamins in association with specific lung cancer histologies, we stratified our analyses by the most common histologic types: small-cell lung cancer and total non-small-cell lung cancer (NSCLC); we further analyzed NSCLC stratified into its major subsets: adenocarcinomas, squamous cell carcinomas, and NSCLC not otherwise specified. All reported $P$ values are two sided and $P<.05$ was considered statistically significant. $P$ values for trend ( $P$ trend) were calculated by treating categorical exposure variables as ordinal in Cox regression models. SAS version 9.4 (SAS Institute, Cary, NC) was used for all statistical analyses. 


\begin{tabular}{|c|c|c|}
\hline Characteristic & $\begin{array}{l}\text { Participants With Lung Cancer } \\
\qquad(\mathrm{n}=808)\end{array}$ & $\begin{array}{l}\text { Participants Without Lung Cancer } \\
\qquad(\mathrm{n}=76,310)\end{array}$ \\
\hline \multicolumn{3}{|l|}{ Age, years } \\
\hline $50-59$ & $142(17.57)$ & $35,242(46.18)$ \\
\hline $60-69$ & 331 (40.97) & 26,423 (34.63) \\
\hline$\geq 70$ & $335(41.46)$ & 14,645 (19.19) \\
\hline \multicolumn{3}{|l|}{ Sex } \\
\hline Female & $359(44.43)$ & $39,710(52.04)$ \\
\hline Male & $449(55.57)$ & $36,600(47.96)$ \\
\hline \multicolumn{3}{|l|}{ Education } \\
\hline Less than high school & 277 (35.33) & 14,979 (19.97) \\
\hline Some college & $326(41.58)$ & 28,705 (38.26) \\
\hline College graduate or beyond & $181(23.09)$ & $31,340(41.77)$ \\
\hline \multicolumn{3}{|l|}{ Race } \\
\hline White & 737 (94.13) & 69,874 (93.16) \\
\hline Nonwhite & $46(5.87)$ & $5,129(6.84)$ \\
\hline \multicolumn{3}{|l|}{ Cigarette smoking } \\
\hline Never & $60(7.51)$ & $36,381(48.06)$ \\
\hline Former ( $\geq 10$ years since quitting) & $334(41.91)$ & $28,030(37.15)$ \\
\hline Recent $(<10$ years since quitting) & $152(19.07)$ & $4,880(6.47)$ \\
\hline Current & $251(31.41)$ & $6,169(8.15)$ \\
\hline \multicolumn{3}{|l|}{ Years of cigarette smoking } \\
\hline 0 & $60(7.53)$ & $36,381(48.15)$ \\
\hline $1-35$ & $169(21.20)$ & 26,934 (35.65) \\
\hline$>35$ & $568(71.27)$ & $12,237(16.20)$ \\
\hline \multicolumn{3}{|l|}{ Pack-years of cigarette smoking } \\
\hline 0 & $60(7.57)$ & $36,381(48.24)$ \\
\hline $1-25$ & $178(22.45)$ & $24,925(33.05)$ \\
\hline$>25$ & 555 (69.99) & $14,103(18.70)$ \\
\hline \multicolumn{3}{|l|}{ Alcohol consumption, g/d } \\
\hline 0 to $<0.5$ & $324(41.91)$ & $28,701(38.58)$ \\
\hline $0.5-1.4$ & 77 (9.96) & $7,932(10.66)$ \\
\hline $1.5-4.9$ & $72(9.31)$ & $10,248(13.78)$ \\
\hline $5.0-9.9$ & $86(11.13)$ & 8,834 (11.88) \\
\hline$>10$ & $214(27.68)$ & $18,676(25.11)$ \\
\hline \multicolumn{3}{|l|}{ Body mass index, $\mathrm{kg} / \mathrm{m}^{2}$} \\
\hline$<25$ & 286 (37.63) & 24,941 (34.38) \\
\hline $25.0-29.9$ & 322 (42.37) & 29,735 (40.99) \\
\hline$\geq 30.0$ & $152(20.00)$ & 17,869 (24.63) \\
\hline \multicolumn{3}{|l|}{ History of COPD } \\
\hline No & $667(82.55)$ & 73,687 (96.59) \\
\hline Yes & $141(17.45)$ & $2,605(3.41)$ \\
\hline \multicolumn{3}{|l|}{ History of cancer } \\
\hline No & $632(78.22)$ & $65,606(85.97)$ \\
\hline Yes & $176(21.78)$ & $10,704(14.03)$ \\
\hline \multicolumn{3}{|c|}{ No. of first-degree relatives with lung cancer } \\
\hline None & $643(80.48)$ & $65,838(87.42)$ \\
\hline 1 & $142(17.77)$ & $8,815(11.71)$ \\
\hline$\geq 2$ & $14(1.75)$ & $655(0.87)$ \\
\hline \multicolumn{3}{|l|}{ NSAID use, 10 -year use } \\
\hline Nonuser & $384(51.47)$ & $36,639(51.87)$ \\
\hline Low $(<4 \mathrm{~d} /$ wk or $<4$ years $)$ & $197(26.41)$ & $20,727(29.34)$ \\
\hline High ( $\geq 4 \mathrm{~d} / \mathrm{wk}$ and $\geq 4$ years) & $165(22.12)$ & $13,276(18.79)$ \\
\hline \multicolumn{3}{|c|}{ Combined hormone therapy (women only), years } \\
\hline Never & $222(66.27)$ & $24,287(65.15)$ \\
\hline $1.0-4.0$ & $33(9.85)$ & $4,776(12.81)$ \\
\hline $4.1-9.9$ & $26(7.76)$ & $3,912(10.49)$ \\
\hline$\geq 10$ & $54(16.12)$ & $4,304(11.55)$ \\
\hline
\end{tabular}

NOTE. Data is presented as No. (\%).

Abbreviations: COPD, chronic obstructive pulmonary disease; NSAID, nonsteroidal anti-inflammatory drug; VITAL, Vitamins and Lifestyle.

\section{RESULTS}

Distributions of participants' baseline characteristics are listed in Table 1. Relative to participants without lung cancer, participants with lung cancer tended to be older, male, and less educated at baseline. Participants with lung cancer also tended to have lower body mass and consumed less alcohol. Participants with lung cancer were more likely to be current cigarette smokers at baseline, have more pack-years of smoking, and had positive histories of chronic obstructive pulmonary disease and cancer. 
Intakes of B vitamins from supplements tended to be higher among women than men $(P<.001)$, but the reverse was true for dietary intakes $(P<.001$; Appendix Table A1, online only). When total intake was considered (ie, from diet and supplements), women had slightly lower intakes of B vitamins $(P<.001)$ than men. On average, participants exceeded the US recommended daily allowance (RDA) for each $\mathrm{B}$ vitamin.

Adjusted HRs and 95\% CIs between supplemental sources of one-carbon metabolism-related B vitamins and lung cancer risk, stratified by sex, are listed in Table 2 . Use of vitamins $B_{6}$ and $B_{12}$ from individual supplement sources was associated with increased lung cancer risk among men only. Compared with nonuse, former use of vitamin $\mathrm{B}_{6}$ from individual supplements was associated with an $84 \%$ increased risk (multivariable-adjusted HR, 1.84 ; 95\% CI, 1.01 to 3.36), whereas former use of vitamin $\mathrm{B}_{12}$ from individual supplements was associated with more than a two-fold lung cancer risk (HR, 2.42; 95\% CI, 1.49 to 3.95). Current use of each supplement at baseline conferred weaker associations with lung cancer risk (HR, 1.37, 95\% CI, 1.03 to 1.84; $\mathrm{HR}, 1.22,95 \% \mathrm{CI}, 0.91$ to 1.64 for vitamins $\mathrm{B}_{6}$ and $\mathrm{B}_{12}$, respectively). When 10 -year average daily dose was considered, the increase in risk was restricted to men in the highest categories of vitamin $\mathrm{B}_{6}(>20 \mathrm{mg} / \mathrm{d}, \mathrm{HR}, 1.82 ; 95 \% \mathrm{CI}, 1.25$ to 2.65$)$ and $\mathrm{B}_{12}$ intakes ( $>55 \mu \mathrm{g} / \mathrm{d}, \mathrm{HR}, 1.98 ; 95 \% \mathrm{CI}, 1.32$ to 2.97 ) compared with nonuse. Additional adjustment for dietary intakes of B vitamins and energy did not change the results, with two exceptions: The associations between former use of $\mathrm{B}_{6}$ and $\mathrm{B}_{12}$ and lung cancer risk were marginally strengthened in men (HR, 2.08, 95\% CI, 1.14 to 3.81; and HR, 2.65, 95\% CI, 1.60 to 4.39 , respectively). Results were unchanged when a 1-year lag analysis was used (data not shown). We further examined diet plus supplemental sources of B vitamins (Appendix Table A2, online only). Consistent with findings from supplemental intakes alone, elevated associations in men were restricted to the upper category of intake.

Table 3 lists associations between 10-year use of B vitamins in male smokers, stratified by smoking status (as defined in Methods). There were too few patients among never smokers to evaluate associations. For vitamin $\mathrm{B}_{6}$ and $\mathrm{B}_{12}$, the HRs contrasting the highest to the lowest categories of 10-year use were considerably stronger among current smokers versus recent or former smokers. For vitamin $\mathrm{B}_{6}, 10$-year use $>20 \mathrm{mg} / \mathrm{d}$ was associated with a near tripling of lung cancer risk among current smokers (HR, 2.93; 95\% CI, 1.50 to 5.72 ; $P$ trend $=.04$ ). For vitamin $B_{12}, 10$-year use $>55 \mathrm{mg} / \mathrm{d}$ was associated with an almost four-fold increased risk of lung cancer among current smokers (HR, 3.71; 95\% CI, 1.77 to $7.74 ; P$ trend $<.01)$. HRs for the highest categories of 10-year use for both vitamins were attenuated among recent and former smokers, although HRs remained $>1.0$. There were no associations for $\mathrm{B}_{9}$ (folic acid).

We further examined the associations of 10-year supplemental B vitamin use with lung cancer risk among men, stratified by lung cancer histologic type (Table 4 ). The increased risk observed in men for use of vitamins $B_{6}$ and $B_{12}$ was generally similar across all histologic subtypes of lung cancer, with the exception of no association with adenocarcinoma.

\section{DISCUSSION}

In this large, prospective analysis of older adults, we report a 30\% to $40 \%$ increased lung cancer risk associated with vitamins $\mathrm{B}_{6}$ and $\mathrm{B}_{12}$ use from individual supplements in men. No association was found in women or for B vitamins from multivitamin sources. Use of vitamin $\mathrm{B}_{6}$ or $\mathrm{B}_{12}$ in high doses (mostly from individual supplements) for an extended period (10 years) was associated with an almost two-fold increased risk of lung cancer in men, and this risk was further strengthened among men who were current smokers at baseline. We found no association between folate intake and lung cancer, which is consistent with most studies investigating dietary $^{9-13}$ or supplemental ${ }^{14,15}$ folate intake, including one prior analysis in the VITAL cohort with shorter follow-up duration. ${ }^{8}$ This could be due to the widespread fortification of foods with folic acid starting in 1997 in the United States ${ }^{16}$ (treated as dietary folate in this study), which would reduce the contrast in intake between supplement users versus nonusers; the fact that individual folate supplements were typically marketed at $100 \%$ of the RDA $(400 \mu \mathrm{g})$ at the time rather than the large doses (often $\geq 10$ times the RDA) at which other B vitamin supplements were marketed; or no true association.

Several studies have examined the associations of $B_{6}$ intake and lung cancer (Supplemental Data). No significant associations have been reported on dietary intake ${ }^{11,13}$ or supplemental use $\mathrm{s}^{3}$; however, inverse associations were reported from studies of serum $\mathrm{B}_{6}$ concentrations. These latter studies reported about half the lung cancer risk in those with higher serum $\mathrm{B}_{6}$ levels. ${ }^{17,18}$ A randomized controlled trial by Ebbing et $\mathrm{al}^{3}$ with four groups $\left(\mathrm{B}_{12}\right.$ plus folic acid, $B_{12}$ plus folic acid plus $B_{6}, B_{6}$ only, and placebo) found no effect of $40 \mathrm{mg} / \mathrm{d}$ of vitamin $\mathrm{B}_{6}$ on lung cancer (HR, 1.06; $95 \% \mathrm{CI}$, 0.62 to 1.82 ). In contrast, we found that supplemental intakes of $B_{6}$ were associated with a $40 \%$ to $82 \%$ increased lung cancer risk in men. Associations were further elevated among smokers. These conflicting results could be explained by either serum measures being a more accurate reflection of vitamin $B_{6}$ intake than the FFQ or serum levels differing between participants with lung cancer and participants without lung cancer because of different absorption, distribution, or catabolism of the circulating nutrient, rather than the total amount they consume. ${ }^{18}$ Evidence supporting the second hypothesis comes from a study reporting that among $\mathrm{B}_{6}$ metabolism markers, it was the inflammation-related changes in a vitamin $\mathrm{B}_{6}$ catabolism marker, the 4-pyridoxic acid/pyridoxal plus pyridoxal $5^{\prime}$-phosphate ratio, that was linked to increased lung cancer risk. ${ }^{19}$

To our knowledge, no prospective study has reported an inverse association between high intake or serum level of vitamin $\mathrm{B}_{12}$ and lung cancer risk (Supplemental Data). ${ }^{3,13,17,18}$ To the contrary, two prospective biomarker studies reported elevated lung cancer risks when comparing the highest versus the lowest categories of serum $\mathrm{B}_{12}$. Johansson et $\mathrm{al}^{18}$ reported an odds ratio of 1.35 (95\% CI, 1.00 to $1.82 ; P$ trend $=.04)$ in both sexes; whereas Hartman et $\mathrm{al}^{17}$ reported no association in men (odds ratio, 1.41; $95 \%$ CI, 0.80 to 2.50 ). Similar to our findings, elevated risks were observed among smokers in the first study. ${ }^{18}$ The randomized trial by Ebbing et $\mathrm{al}^{3}$ reported an HR of 1.59 (95\% CI, 0.92 to 2.75) among those randomly assigned to the vitamin $\mathrm{B}_{12}$ plus folic acid groups versus those who did not receive such treatment. Notably, 


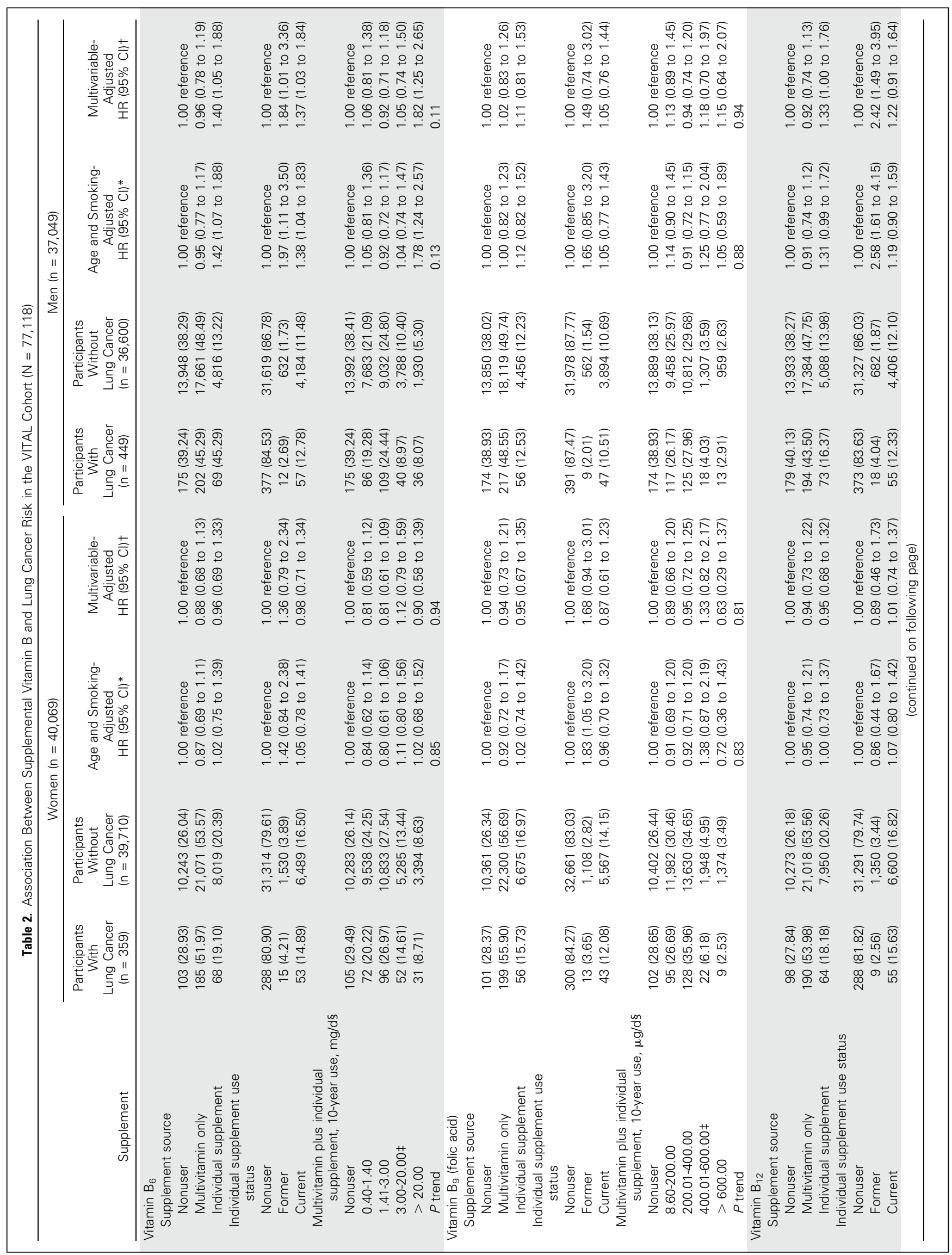




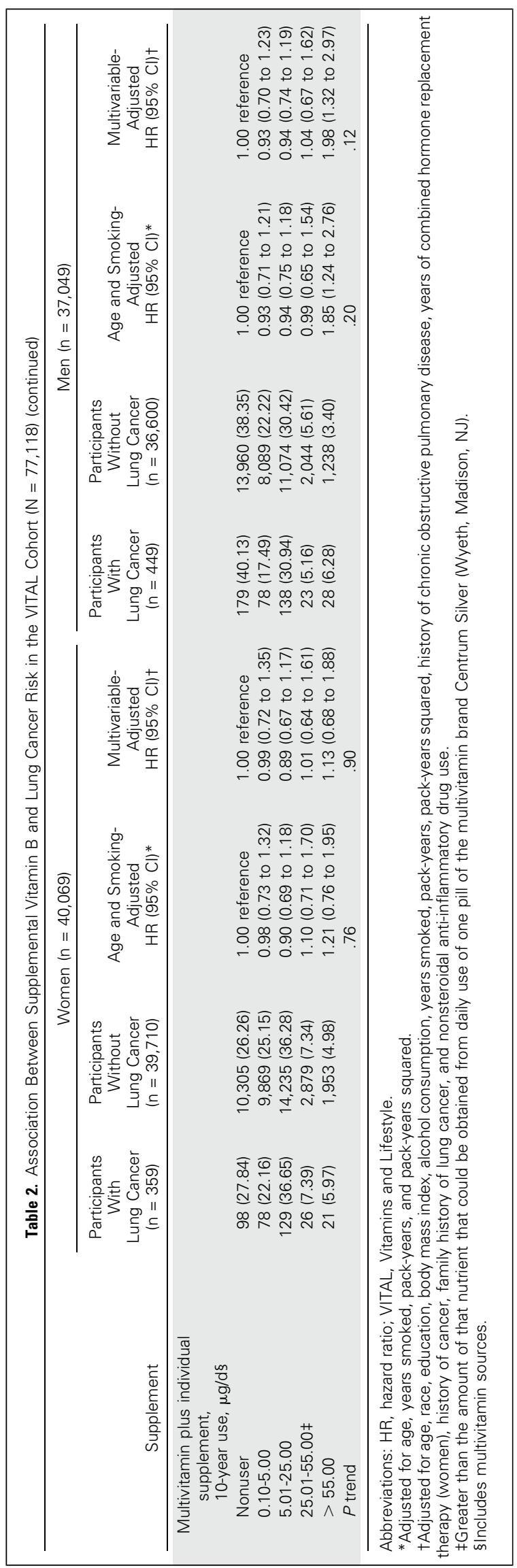


Table 3. Associations Between Supplemental B Vitamins and Lung Cancer Risk in Men, Stratified on Smoking Status

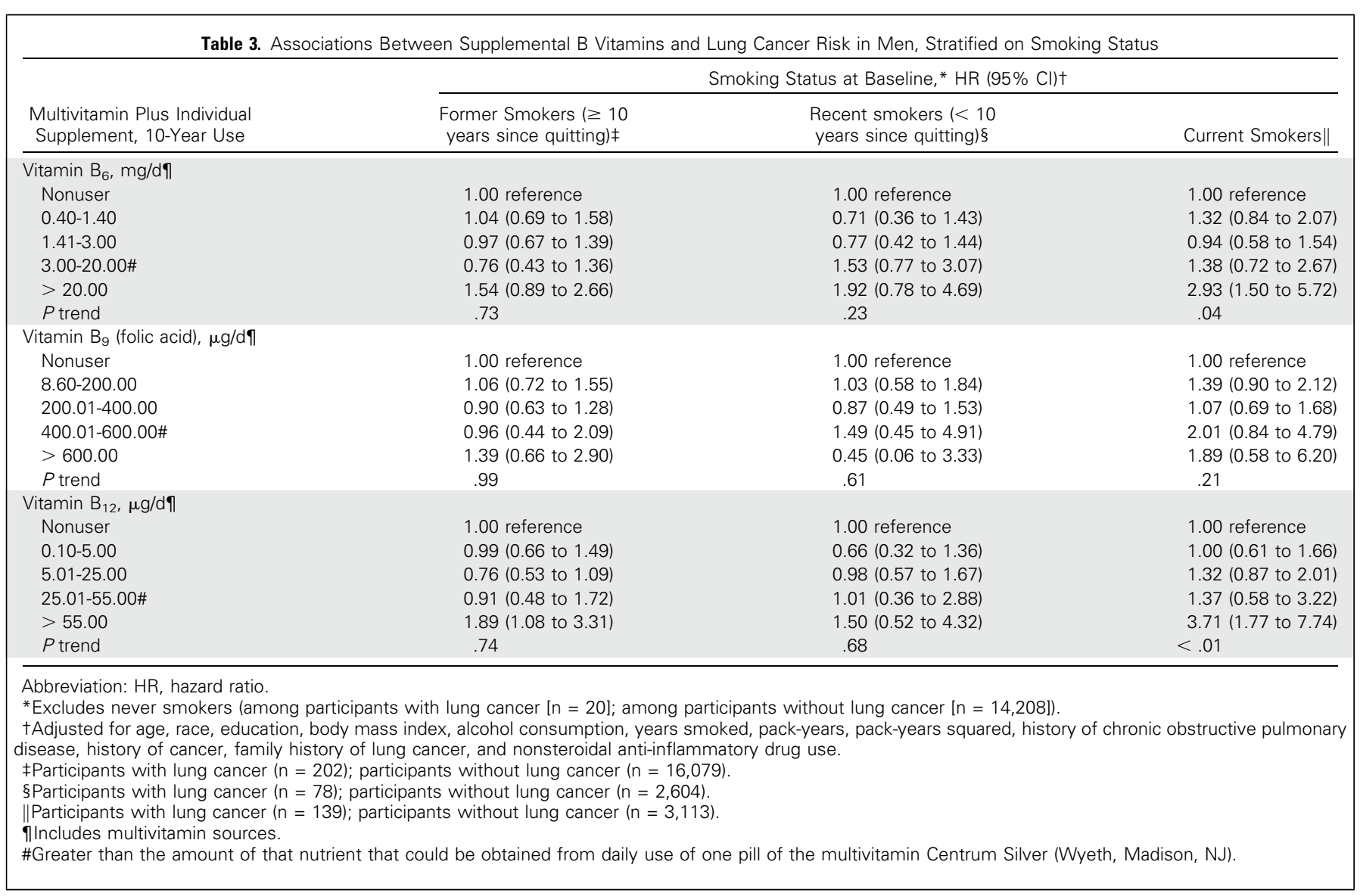

the $\mathrm{B}_{12}$ dose used in this trial, $0.4 \mathrm{mg} / \mathrm{d}$ (ie, $40 \mu / \mathrm{d}$ ), was greater than the cut-off dose of $>55 \mu / \mathrm{d}$ for which we found a two-fold increased risk, albeit over a shorter period.

We found that $\mathrm{B}_{6}$ and $\mathrm{B}_{12}$ had sex- and source-specific associations with lung cancer risk. In addition, the association in men was more pronounced in cigarette smokers. Shi et $\mathrm{al}^{20}$ reported that the genetic polymorphisms of an important enzyme involved in folate metabolism, 5,10-methylenetetrahydrofolate reductase, interacted differently between men and women with dietary vitamin $\mathrm{B}_{6}$ and $\mathrm{B}_{12}$ intakes, cigarette smoking, and lung cancer. Men and women have different susceptibility to tobacco-induced lung cancer and supplementation with high-dose vitamins $\mathrm{B}_{6}$ and $\mathrm{B}_{12}$ for longer duration may support more rapid cell growth and promote carcinogenesis in already mutated cells in smoking men. Because androgen signaling regulates key enzymes involved in the one-carbon metabolism pathways, the increase of androgen levels or activity in men may lead to a more profound effect. ${ }^{21} \mathrm{~A}$ study by Suzuki et $\mathrm{al}^{22}$ reported significant interaction between a polymorphism in methionine synthase reductase and smoking, resulting in synergistically increased lung cancer risk. This evidence may help explain our observations.

In addition to its prospective nature and near-complete follow-up, our study has the advantage of more detailed assessment of supplement use than previous studies, including years of use over the 10 years before baseline, source (multivitamins, individual supplements, and mixtures), frequency, and dose. We summarized this information into 10 -year average dose per day as the main exposure of interest because this may better reflect the long induction period of lung cancer. However, if 10-year exposure is too short to reflect use before the induction period, we would expect some nondifferential measurement error to result. Nevertheless, the self-reported supplemental vitamin use has been validated and proved to have high reliability (3-month test-retest reliability of the 10 -year $\mathrm{B}$ vitamin dose variables were 0.80 to 0.84 ) and validity (correlations of self-reported current B vitamin doses with vitamin bottle labels in participants' homes were 0.69 to $0.76) .{ }^{23}$ In addition, we created a model to more strongly control for the effect of cigarette smoking, and controlled for other important confounding factors. However, we were limited by lack of information on occupational or environmental lung cancer risk factors, as well as a lack of serum B-vitamin measurements to assess the prevalence of suboptimal intakes or to complement our findings from self-reported intake.

The biology of the $\mathrm{B}$ vitamins involved in one-carbon metabolism suggests that intakes should be beneficial to cancer risk. Folate serves as a methyl donor in the process of nucleotide synthesis and methylation reactions. ${ }^{24}$ Deficiencies in these nutrients may result in greater chances of DNA damage, possibly influencing gene expression through aberrant methylation patterns, leading to initiated cells or promoting already initiated cells. $^{24,25}$ Intakes of B vitamins that meet recommended levels among those who are deficient should be useful for these reasons. On the other hand, excess supplement of folic acid and vitamin $B_{12}$ 
Table 4. Associations Between Supplemental B Vitamins and Lung Cancer Risk in Men, Stratified by Lung Cancer Histologic Type

\begin{tabular}{|c|c|c|c|c|c|}
\hline \multirow[b]{2}{*}{$\begin{array}{l}\text { Multivitamin Plus Individual } \\
\text { Supplement, } 10 \text {-Year Use }\end{array}$} & \multicolumn{4}{|c|}{ NSCLC, HR $(95 \% \mathrm{Cl})^{*} \dagger(\mathrm{n}=331)$} & \multirow{2}{*}{$\begin{array}{c}\text { SCLC, } \\
\mathrm{HR}(95 \% \mathrm{Cl})^{*} \\
(\mathrm{n}=68)\end{array}$} \\
\hline & Total NSCLC & $\begin{array}{l}\text { Adenocarcinoma } \\
\quad(n=131)\end{array}$ & $\begin{array}{l}\text { Squamous Cell } \\
\text { Carcinoma }(n=87)\end{array}$ & $\begin{array}{l}\text { NSCLC, NOS } \\
(n=104)\end{array}$ & \\
\hline \multicolumn{6}{|l|}{ Vitamin $B_{6}, \mathrm{mg} / \mathrm{d} \neq$} \\
\hline Nonuser & 1.00 reference & 1.00 reference & 1.00 reference & 1.00 reference & 1.00 reference \\
\hline $0.40-1.40$ & $0.87(0.63$ to 1.21$)$ & 1.09 (0.66 to 1.82$)$ & $0.51(0.24$ to 1.10$)$ & $0.91(0.51$ to 1.60$)$ & $2.72(1.43$ to 5.15$)$ \\
\hline $1.41-3.00$ & $0.88(0.66$ to 1.18$)$ & $1.13(0.72$ to 1.79$)$ & $0.82(0.46$ to 1.43$)$ & $0.75(0.44$ to 1.27$)$ & 1.18 (0.57 to 2.45$)$ \\
\hline $3.00-20.00 \S$ & $1.06(0.71$ to 1.58$)$ & 1.75 (1.01 to 3.03$)$ & $0.66(0.26$ to 1.69$)$ & $0.66(0.28$ to 1.55$)$ & 1.15 (0.39 to 3.44$)$ \\
\hline$>20.00$ & 1.96 (1.29 to 2.96$)$ & $1.36(0.61$ to 3.03$)$ & $2.38(1.13$ to 5.02$)$ & 2.62 (1.36 to 5.04$)$ & $1.61(0.47$ to 5.56$)$ \\
\hline$P$ trend & .10 & .11 & .47 & .42 & .69 \\
\hline \multicolumn{6}{|l|}{ Vitamin $B_{9}$ (folic acid), $\mu \mathrm{g} / \mathrm{d} \neq$} \\
\hline Nonuser & 1.00 reference & 1.00 reference & 1.00 reference & 1.00 reference & 1.00 reference \\
\hline $8.60-200.00$ & $0.96(0.72$ to 1.30$)$ & $1.26(0.81$ to 1.98$)$ & $0.58(0.29$ to 1.14$)$ & $0.95(0.55$ to 1.61$)$ & 2.77 (1.51 to 5.10$)$ \\
\hline $200.01-400.00$ & $1.03(0.78$ to 1.34$)$ & $1.17(0.76$ to 1.79$)$ & $1.01(0.61$ to 1.69$)$ & $0.99(0.61$ to 1.60$)$ & $0.71(0.32$ to 1.62$)$ \\
\hline $400.01-600.00 \S$ & 1.07 (0.57 to 1.98$)$ & $0.78(0.24$ to 2.51$)$ & $1.07(0.33$ to 3.50$)$ & $1.23(0.44$ to 3.47$)$ & 1.56 (0.36 to 6.81$)$ \\
\hline$>600.00$ & 1.01 (0.49 to 2.07$)$ & 0.69 (0.17 to 2.86$)$ & 0.46 (0.06 to 3.38$)$ & 1.95 (0.76 to 4.99$)$ & $3.12(0.90$ to 10.82$)$ \\
\hline$P$ trend & .83 & .95 & .79 & .42 & .64 \\
\hline \multicolumn{6}{|l|}{ Vitamin $B_{12}, \mu \mathrm{g} / \mathrm{d} \neq$} \\
\hline Nonuser & 1.00 reference & 1.00 reference & 1.00 reference & 1.00 reference & 1.00 reference \\
\hline $0.10-5.00$ & $0.78(0.56$ to 1.09$)$ & 1.12 (0.69 to 1.84$)$ & $0.45(0.20$ to 1.10$)$ & $0.68(0.37$ to 1.25$)$ & 2.29 (1.18 to 4.43 ) \\
\hline $5.01-25.00$ & $0.92(0.70$ to 1.20$)$ & $1.26(0.83$ to 1.91$)$ & 0.86 (0.50 to 1.46$)$ & $0.71(0.43$ to 1.17$)$ & 1.31 (0.66 to 2.59$)$ \\
\hline $25.01-55.00 \S$ & $1.03(0.62$ to 1.71$)$ & $0.84(0.33$ to 2.12$)$ & 0.88 (0.31 to 2.49$)$ & $1.07(0.45$ to 2.52$)$ & $1.47(0.43$ to 5.04$)$ \\
\hline$>55.00$ & 2.09 (1.33 to 3.27$)$ & $1.30(0.51$ to 3.30$)$ & 2.83 (1.29 to 6.22$)$ & 2.69 (1.34 to 5.43$)$ & $2.43(0.70$ to 8.40$)$ \\
\hline$P$ trend & .13 & .47 & .25 & .33 & .26 \\
\hline \multicolumn{6}{|c|}{$\begin{array}{l}\text { NOTE. The number of participants with lung cancer does not add up to } 449 \text { because } 50 \text { participants with other histologies were excluded; participants without lung } \\
\text { cancer ( } n=36,600) \text {. } \\
\text { Abbreviations: HR, hazard ratio; NOS, not otherwise specified; NSCLC, non-small-cell lung cancer; SCLC, small-cell lung cancer. } \\
\text { *Adjusted for age, race, education, body mass index, alcohol consumption, years smoked, pack-years, pack-years squared, history of chronic-obstructive pulmonary } \\
\text { disease, history of cancer, family history of lung cancer, and nonsteroidal anti-inflammatory drug use. } \\
\text { †Includes nine men with large-cell lung cancer. } \\
\text { łIncludes multivitamin sources. } \\
\S \text { Greater than the amount of that nutrient that could be obtained from daily use of one pill of the multivitamin brand Centrum Silver (Wyeth, Madison, NJ). }\end{array}$} \\
\hline
\end{tabular}

was found to be associated with changes in DNA methylation of several genes that could be reactivated or deregulated during carcinogenesis. ${ }^{26}$ Like colorectal cancer, these $\mathrm{B}$ vitamins may have a double-edged sword effect on lung cancer by possessing dual modulatory effects that are time and dose dependent ${ }^{27}$. Most people in the United States should have sufficient intakes from diet, particularly for folate, which has been added to foods. Nonetheless, half of the US adult population uses one or more dietary supplements. ${ }^{16,28}$ Our study found that consuming high-dose individual $\mathrm{B}_{6}$ and $\mathrm{B}_{12}$ vitamin supplements over a 10-year period is associated with increased lung cancer risk, especially in male smokers. Consistent with prior evidence of harm for other vitamin supplements on lung cancer risk in smokers, ${ }^{29-32}$ the associations we observed provide evidence that high-dose $B_{6}$ and $B_{12}$ supplements should not be taken for lung cancer prevention and, in fact, may increase risk of this disease in men.

\section{AUTHORS' DISCLOSURES OF POTENTIAL CONFLICTS OF INTEREST}

Disclosures provided by the authors are available with this article at jco.org.

\section{AUTHOR CONTRIBUTIONS}

Financial support: Emily White

Provision of study materials or patients: Emily White

Collection and assembly of data: Emily White

Conception and design: All authors

Data analysis and interpretation: Theodore M. Brasky, Emily White

Manuscript writing: All authors

Final approval of manuscript: All authors

Accountable for all aspects of the work: All authors

\section{REFERENCES}

1. Ferlay J, Shin HR, Bray F, et al: Estimates of worldwide burden of cancer in 2008: GLOBOCAN 2008. Int J Cancer 127:2893-2917, 2010

2. Kim YI: Folate and DNA methylation: A mechanistic link between folate deficiency and colorectal cancer? Cancer Epidemiol Biomarkers Prev 13:511-519, 2004

3. Ebbing $\mathrm{M}$, Bønaa $\mathrm{KH}$, Nygård $\mathrm{O}$, et al: Cancer incidence and mortality after treatment with folic acid and vitamin B12. JAMA 302:2119-2126, 2009
4. White $E$, Patterson RE, Kristal $A R$, et al: VITamins And Lifestyle cohort study: Study design and characteristics of supplement users. Am J Epidemiol 159:83-93, 2004

5. Kristal AR, Feng Z, Oberman A, et al: Associations of race/ethnicity, education, and dietary intervention with the validity and reliability of a food frequency questionnaire: the Women's Health Trial Feasibility Study in Minority Populations. Am J Epidemiol 146:856-859, 1997

6. Patterson RE, Kristal $A R$, Tinker $L F$, et al: Measurement characteristics of the Women's Health Initiative food frequency questionnaire. Ann Epidemiol 9:178-187, 1999
7. Field RW, Smith BJ, Platz CE, et al: Lung cancer histologic type in the Surveillance, Epidemiology, and End Results registry versus independent review. J Natl Cancer Inst 96:1105-1107, 2004

8. Slatore CG, Littman AJ, Au DH, et al: Longterm use of supplemental multivitamins, vitamin $\mathrm{C}$, vitamin $E$, and folate does not reduce the risk of lung cancer. Am J Respir Crit Care Med 177:524-530, 2008

9. Yuan JM, Stram DO, Arakawa K, et al: Dietary cryptoxanthin and reduced risk of lung cancer: The Singapore Chinese Health Study. Cancer Epidemiol Biomarkers Prev 12:890-898, 2003 
10. Cho E, Hunter DJ, Spiegelman D, et al: Intakes of vitamins $A, C$ and $E$ and folate and multivitamins and lung cancer: A pooled analysis of 8 prospective studies. Int J Cancer 118:970-978, 2006

11. Bassett JK, Hodge AM, English DR, et al: Dietary intake of $B$ vitamins and methionine and risk of lung cancer. Eur J Clin Nutr 66:182-187, 2012

12. Kabat GC, Miller AB, Jain $M$, et al: Dietary intake of selected $B$ vitamins in relation to risk of major cancers in women. $\mathrm{Br} \mathrm{J}$ Cancer 99:816-821, 2008

13. Takata $Y$, Cai $Q$, Beeghly-Fadiel $A$, et al: Dietary $B$ vitamin and methionine intakes and lung cancer risk among female never smokers in China Cancer Causes Control 23:1965-1975, 2012

14. Shen $H$, Wei $Q$, Pillow $P C$, et al: Dietary folate intake and lung cancer risk in former smokers: A case-control analysis. Cancer Epidemiol Biomarkers Prev 12:980-986, 2003

15. Roswall N, Olsen A, Christensen J, et al: Source-specific effects of micronutrients in lung cancer prevention. Lung Cancer 67:275-281, 2010

16. Martínez ME, Jacobs ET, Baron JA, et al: Dietary supplements and cancer prevention: Balancing potential benefits against proven harms. J Nat Cancer Inst 104:732-739, 2012

17. Hartman TJ, Woodson $K$, Stolzenberg-Solomon $\mathrm{R}$, et al: Association of the B-vitamins pyridoxal 5'phosphate $(\mathrm{B}(6)), \mathrm{B}(12)$, and folate with lung cancer risk in older men. Am J Epidemiol 153:688-694, 2001
18. Johansson $M, R E L$ ton $C$, Ueland $P M$, et al: Serum $B$ vitamin levels and risk of lung cancer. JAMA 303:2377-2385, 2010

19. Zuo H, Ueland PM, Eussen SJ, et al: Markers of vitamin B6 status and metabolism as predictors of incident cancer: The Hordaland Health Study. Int J Cancer 136:2932-2939, 2015

20. Shi Q, Zhang Z, Li G, et al: Sex differences in risk of lung cancer associated with methylenetetrahydrofolate reductase polymorphisms. Cance Epidemiol Biomarkers Prev 14:1477-1484, 2005

21. Corbin JM, Ruiz-Echevarría MJ: One-carbon metabolism in prostate cancer: The role of androgen signaling. Int J Mol Sci 17(8), 2016

22. Suzuki T, Matsuo K, Hiraki A, et al: Impact of one-carbon metabolism-related gene polymorphisms on risk of lung cancer in Japan: A case control study. Carcinogenesis 28:1718-1725, 2007

23. Satia-Abouta J, Patterson RE, King IB, et al: Reliability and validity of self-report of vitamin and mineral supplement use in the vitamins and lifestyle study. Am J Epidemiol 157:944-954, 2003

24. Kim YI: Folate and colorectal cancer: an evidence-based critical review. Mol Nutr Food Res 51:267-292, 2007

25. Das PM, Singal R: DNA methylation and cancer. J Clin Oncol 22:4632-4642, 2004

26. Kok DEG, Dhonukshe-Rutten RAM, Lute C, et al: The effects of long-term daily folic acid and vitamin B12 supplementation on genome-wide DNA methylation in elderly subjects. Clin Epigenetics 7: 121, 2015

27. Kim YI: Folate: A magic bullet or a double edged sword for colorectal cancer prevention? Gut 55:1387-1389, 2006

28. Kantor ED, Rehm CD, Du M et al: Trends in dietary supplement use among US adults from 19992012. JAMA 316:1464-1474, 2016

29. Alpha-Tocopherol, Beta Carotene Cancer Prevention Study Group: The effect of vitamin E and beta carotene on the incidence of lung cancer and other cancers in male smokers. N Engl J Med 330: 1029-1035, 1994

30. Virtamo J, Pietinen $P$, Huttunen JK, et al: Incidence of cancer and mortality following alphatocopherol and beta-carotene supplementation: A postintervention follow-up. JAMA 290:476-485, 2003

31. Omenn GS, Goodman GE, Thornquist MD et al: Effects of a combination of beta carotene and vitamin A on lung cancer and cardiovascular disease. N Engl J Med 334:1150-1155, 1996

32. Goodman GE, Thornquist MD, Balmes J, et al: The Beta-Carotene and Retinol Efficacy Trial: Incidence of lung cancer and cardiovascular disease mortality during 6-year follow-up after stopping betacarotene and retinol supplements. J Natl Cancer Inst 96:1743-1750, 2004

\section{Affiliations}

Theodore M. Brasky, The Ohio State University College of Medicine, Columbus, OH; Theodore M. Brasky and Emily White, Fred Hutchinson Cancer Research Center, Seattle, WA; Chi-Ling Chen, College of Public Health and College of Medicine, National Taiwan University, Taipei, Taiwan.

\section{Support}

Supported by the National Institutes of Health Grants No. R25-CA094880 (National Cancer Institute [NCI]) and K05-CA154337 (NCI and Office of Dietary Supplements). 


\section{AUTHORS' DISCLOSURES OF POTENTIAL CONFLICTS OF INTEREST}

Long-Term, Supplemental, One-Carbon Metabolism-Related Vitamin B Use in Relation to Lung Cancer Risk in the Vitamins and Lifestyle (VITAL) Cohort

The following represents disclosure information provided by authors of this manuscript. All relationships are considered compensated. Relationships are self-held unless noted. I = Immediate Family Member, Inst = My Institution. Relationships may not relate to the subject matter of this manuscript. For more information about ASCO's conflict of interest policy, please refer to www.asco.org/rwc or ascopubs.org/jco/site/ifc.

Theodore M. Brasky

No relationship to disclose

\section{Emily White}

No relationship to disclose

\section{Chi-Ling Chen}

No relationship to disclose 


\section{Appendix}

\begin{tabular}{|c|c|c|c|c|}
\hline Study and Year & & & & $\mathrm{RR}(95 \% \mathrm{Cl})$ \\
\hline \multicolumn{5}{|l|}{ Supplements } \\
\hline \multicolumn{2}{|l|}{ Ebbing $\mathrm{M}$ et al., $2009^{3}$} & - & & 1.06 (0.62 to 1.82$)$ \\
\hline \multicolumn{5}{|l|}{ Diet } \\
\hline Bassett JK et al., $2012^{11}$ & & 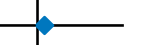 & & $1.03(0.74$ to 1.43$)$ \\
\hline Takata Y et al., $2012^{13}$ & & 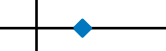 & & 1.21 (0.84 to 1.74$)$ \\
\hline \multicolumn{5}{|l|}{ Serum } \\
\hline Hartman TJ et al., $2001^{17}$ & $\longrightarrow$ & - & & 0.51 (0.28 to 0.93 ) \\
\hline \multirow[t]{2}{*}{ Johansson M et al., $2010^{18}$} & $\longrightarrow$ & & & 0.50 (0.36 to 0.69$)$ \\
\hline & $0.50 \quad 0.66$ & 1.00 & 2.00 & 3.00 \\
\hline
\end{tabular}

Fig A1. Forest plot of previous studies of vitamin $B_{6}$ and lung cancer risk, stratified on exposure type.

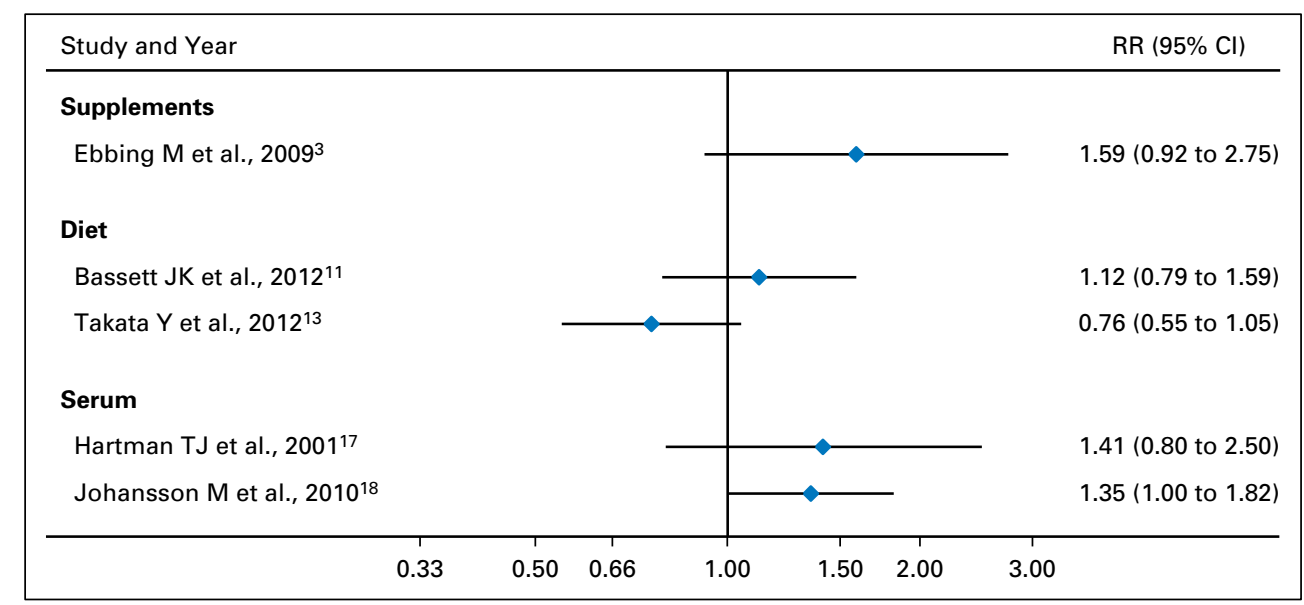

Fig A2. Forest plot of previous studies of vitamin $B_{12}$ and lung cancer risk, stratified on exposure type.

\begin{tabular}{|c|c|c|c|c|}
\hline \multirow[b]{2}{*}{ Vitamin B Intake } & \multicolumn{3}{|c|}{ Median Intake (IQR) } & \multirow[b]{2}{*}{$P^{*}$} \\
\hline & Overall & Women $(n=40,069)$ & Men $(n=37,049)$ & \\
\hline \multicolumn{5}{|l|}{ Supplements } \\
\hline $\mathrm{B}_{6}, 10$-year use, mg/d & $1.00(2.50)$ & $1.40(2.90)$ & $0.60(2.20)$ & $<.001$ \\
\hline $\mathrm{B}_{9}$ (folic acid), 10-year use, $\mu \mathrm{g} / \mathrm{d}$ & $157.14(400.00)$ & $200.00(400.00)$ & $80.00(400.00)$ & $<.001$ \\
\hline$B_{12}, 10$-year use, $\mu \mathrm{g} / \mathrm{d}$ & $3.90(11.70)$ & $5.00(12.81)$ & $3.00(9.80)$ & $<.001$ \\
\hline \multicolumn{5}{|l|}{ Diet } \\
\hline $\mathrm{B}_{6}, \mathrm{mg} / \mathrm{d}$ & $1.91(1.16)$ & $1.59(0.87)$ & $2.32(1.22)$ & $<.001$ \\
\hline$B_{9}, \mu g / d$ & $415.78(254.15)$ & $345.78(189.77)$ & $505.15(270.21)$ & $<.001$ \\
\hline$B_{12}, \mu \mathrm{g} / \mathrm{d}$ & $6.42(4.92)$ & $5.23(3.75)$ & $7.97(5.57)$ & $<.001$ \\
\hline \multicolumn{5}{|l|}{ Diet plus supplements, 10 -year intake } \\
\hline $\mathrm{B}_{6}, \mathrm{mg} / \mathrm{d}$ & $3.26(2.91)$ & 3.09 (3.06) & $3.42(2.72)$ & $<.001$ \\
\hline $\mathrm{B}_{9}$ (folic acid), $\mu \mathrm{g} / \mathrm{d}$ & $843.41(623.91)$ & 781.65 (609.67) & $901.01(649.51)$ & $<.001$ \\
\hline $\mathrm{B}_{12}, \mu \mathrm{g} / \mathrm{d}$ & $11.81(13.30)$ & $10.94(13.46)$ & $12.65(13.09)$ & $<.001$ \\
\hline
\end{tabular}




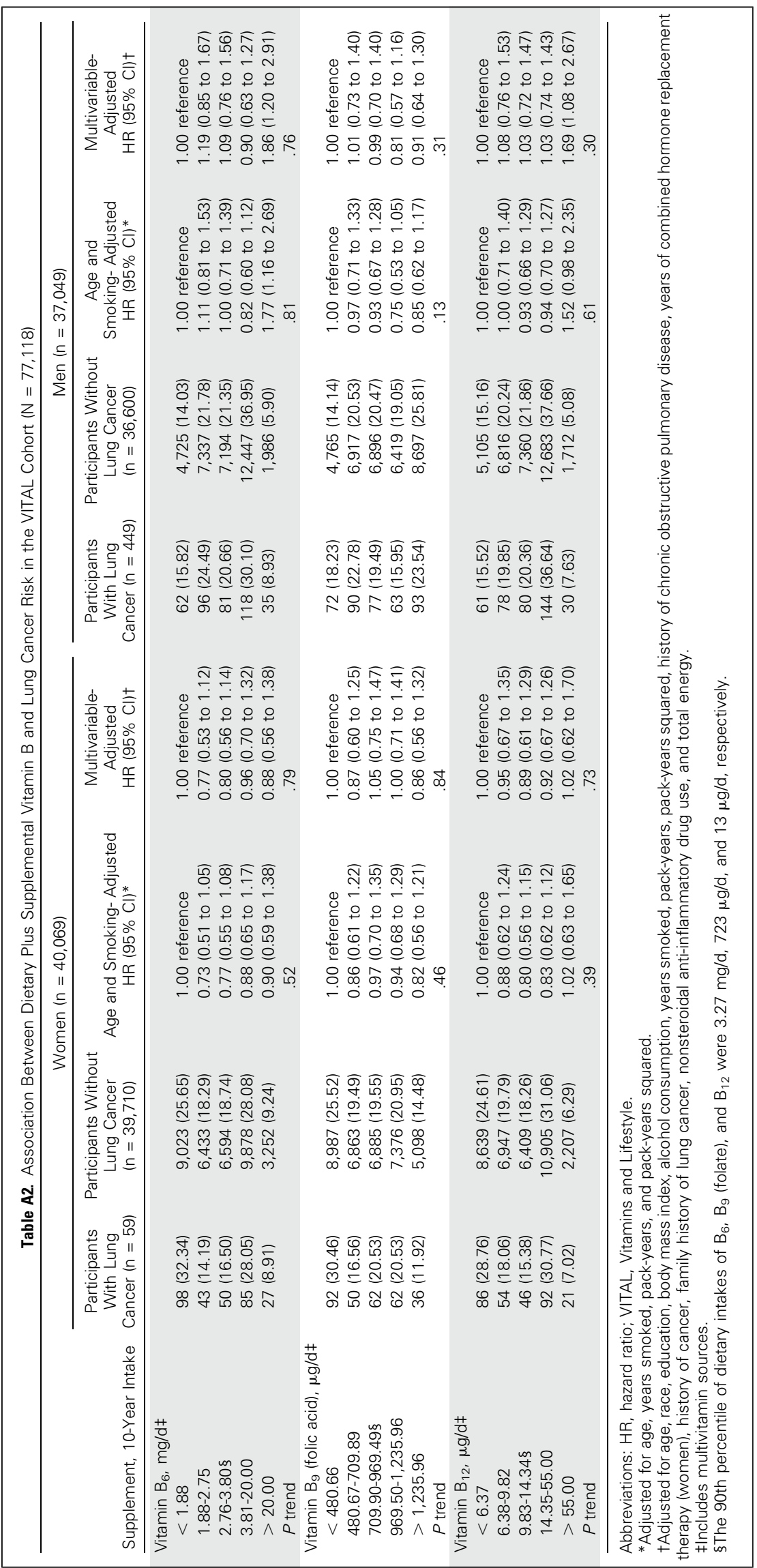

